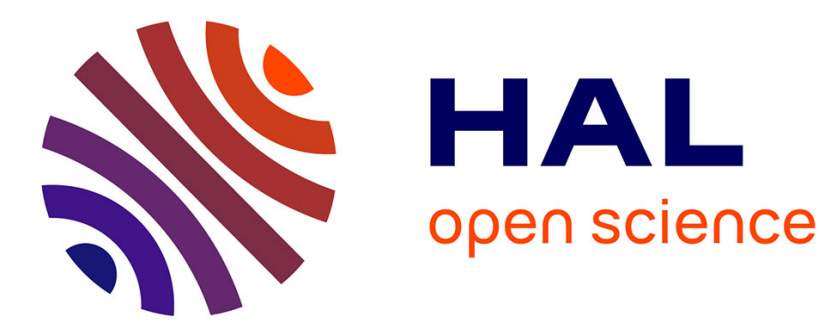

\title{
Large-volume conventional magnetic shields
}

D. Cohen

\section{- To cite this version:}

D. Cohen. Large-volume conventional magnetic shields. Revue de Physique Appliquée, 1970, 5 (1), pp.53-58. 10.1051/rphysap:019700050105300 . jpa-00243375

\section{HAL Id: jpa-00243375 https://hal.science/jpa-00243375}

Submitted on 1 Jan 1970

HAL is a multi-disciplinary open access archive for the deposit and dissemination of scientific research documents, whether they are published or not. The documents may come from teaching and research institutions in France or abroad, or from public or private research centers.
L'archive ouverte pluridisciplinaire HAL, est destinée au dépôt et à la diffusion de documents scientifiques de niveau recherche, publiés ou non, émanant des établissements d'enseignement et de recherche français ou étrangers, des laboratoires publics ou privés. 


\title{
LARGE-VOLUME GONVENTIONAL MAGNETIG SHIELDS
}

\author{
By D. COHEN, \\ Massachusetts Institute of Technology, Francis Bitter National Magnet Laboratory ( ${ }^{\mathbf{1}}$ ), Cambridge, Massachusetts (U.S.A.).
}

Résumé. - La demande croissante en zones de protection à champ faible de large volume a conduit à la construction de nombreuses chambres protégées contre des radiations magnétiques. La plupart d'entre elles ont été du type cubique, à deux couches de moly-permalloy, mais plusieurs ont utilisé trois couches, comme celle qui a été construite par l'auteur il y a environ trois ans. Cette chambre utilise plusieurs innovations y compris une technique de "shaking" (secousses) permettant d'accroître la perméabilité du moly-permalloy. Les caractéristiques de protection et les performances de cette chambre ont été mesurées et les résultats seront discutés dans le texte. Ces mesures indiquent les améliorations qui pourraient être faites avec profit dans les chambres de protection, si l'on voulait aller jusqu'aux limites de protection pour des écrans conventionnels (non superconducteurs). Au MIT, nous avons décidé de construire une telle chambre limitée, à faibles radiations, dans laquelle nous espérons atteindre une amplitude du vecteur $B$ de $1 \times 10^{-8}$ gauss (rms, y compris dc) au centre de la chambre. Cette chambre est maintenant en construction [2] et deviendra une installation nationale. Sa forme est approximativement sphérique et comporte 26 côtés. Elle comporte trois couches de moly-permalloy et deux couches d'aluminium pur. Les diamètres intérieurs et extérieurs sont de 2,5 mètreset 4,0 mètres respectivement. Les traits particuliers et les détails de conception de cette chambre seront discutés dans le texte, ainsi que les utilisations prévues de la chambre au cours des prochaines années.

Abstract. - Increasing demand for low-field regions of large volumes has resulted in the construction of many magnetically-shielded walk-in rooms. Most have been of the cubic, two-layer high- $\mu$ type, but several have used three layers, including one built by this author about three years ago. This room used several innovations, including "shaking" to increase the permeability of the magnetic sheets. The shielding characteristics and performance of this room were measured in some detail, and the results of these measurements will be discussed. These results indicate the improvements in room shielding which could profitably be made if one wished to push to the shielding limit for conventional (non-superconducting) walk-in shields. At MIT, we decided to build such a limiting low-field room in which we hope eventually to reach a $B$-vector amplitude of $1 \times 10^{-8}$ gauss (rms, including dc) at the room center. This room is now under construction $\left({ }^{2}\right)$ and will be a national facility. It is roughly spherical in shape, with 26 sides, and has three layers of high- $\mu$ sheets and two layers of pure aluminium. The inner and outer diameters are 2.5 meters and 4.0 meters. The concepts and design details of this room will be discussed, along with the planned uses of this room for the next several years.

I will divide this talk into three parts. Part I will briefly deal with some general ideas and concepts of magnetic shields; part II will deal with some details of both the theory and practice of large-volume shields; part III will be a description of the shielded room now under construction at the Francis Bitter National Magnet Laboratory.

I. General Ideas and Concepts. - Most of us know that there is an increasing demand for volumes or regions which are shielded against both dc and ac magnetic fields. By magnet fields we here mean the $B$-vector. (At high frequencies the $E$-vector always accompanies the $B$-vector; hence, magnetic shielding and electrostatic shielding are one and the same thing. At very low frequencies these two vectors can exist almost independently and are shielded separately.) This increasing demand is due to magnetometer testing, checking demagnetization of spacecraft components,

(1) Supported by the U.S. Air Force Office of Scientific Research.

(2) Partially supported by the U.S. Office of Naval Research. measurements on geophysical samples, extremely sensitive physics experiments involving general relativity, measurements of magnetic fields from natural ion currents in humans, and other needs in the scientific and engineering community. Now without using superconductivity there are three phenomena which can be used to produce these regions of low magnetic fields; these phenomena can be used separately or together.

The first phenomena is ferromagnetism. The region of interest is partially or completely enclosed by one or more ferromagnetic shells; this type of shielding is effective in the frequency range from dc to $>1 \mathrm{MHz}$. The second phenomenon is that of induced eddycurrents. The region of interest is partially or completely enclosed by one or more shells of good conductor; this type of shielding acts only on ac, and increases in efficiency with increasing frequency. The third phenomenon may be called 'active shielding" and involves the production of fields from artificial currents; these fields act in a way which oppose or counterbalance the external fields. A magnetometer, usually 3-dimensional, at the position of best shielding provides amplifield output currents which are passed through coils 


\section{Ferromagnetic Shielding Theory}

$$
\begin{array}{ll}
\text { One spherical shell : } S=\frac{1.3 \mu t}{d} & \begin{cases}\mu=\text { permeability } \\
t=\text { thickness } \\
d=\text { diameter }\end{cases} \\
\text { Two spherical shells : } S=\left(\frac{1.3 \mu t}{d_{\mathrm{av}}}\right)^{2}\left(1-\frac{d_{\mathrm{i}}^{3}}{d_{0}^{3}}\right) & \left\{\begin{array}{l}
d_{\mathrm{av}}=\text { average diameter } \\
d_{\mathrm{i}}=\text { inner diameter } \\
d_{0}=\text { outer diameter }
\end{array}\right.
\end{array}
$$

For cubical shells : $\quad$ replace 1.3 by 0.7

FIG. 1. - Simplified formulae for spheres and cubes. $S$ is called the shielding factor and is the ratio of the external $B$-vector amplitude, assumed spatially uniform without the shield, to the $B$-vector amplitude at the center of the shielded volume. For a cube $d$ is the length of a side.

arranged in some optimal fashion around the region of interest. The electronic system is arranged to produce negative feedback so that the $B$-vector components at the magnetometer are almost zero. Active shielding is effective from dc up to frequencies near the resonance of the coils; at higher frequencies special phase-shifting circuits would be necessary. Shielding provided by superconductivity involves two phenomena. The Meissner effect is different from the three phenomena just mentioned; the phenomenon of induced eddy-currents for superconductors is the same as for normal conductors except the zero resistivity results in persistent currents or shielding against dc.

Which combination of the three methods of conventional shielding should be used, or whether superconducting shielding is preferable depends on the allowable volume and field within the shield. For example, if one needed $\sim 1 \times 10^{-6}$ gauss (ac, rms) and could tolerate $\sim 1 \times 10^{-5}$ gauss $\mathrm{dc}$, and a volume of $3 \mathrm{~m} \times 3 \mathrm{~m} \times 3 \mathrm{~m}$, then a conventional shield using both ferromagnetic and conducting shells is most economical. On the other hand, if one needed $\sim 1$ $\times 10^{-8}$ gauss ( $\mathrm{rms}$, both dc and ac) in a $20 \mathrm{~cm}^{3}$ volume, then a superconducting shield is the most economical. For the remainder of this talk I will consider only large-volume shields, that is, shielded volumes that are big enough to contain a standing man. At this time the cost of making such large shields with a superconducting shell and door system is almost prohibitive $(>\$ 500,000)$, so I'll talk only about conventional large-volume shields.

\section{Some Theory and Practice of Large-Volume}

Shields. - In dealing with the theory, we will omit eddy-current and active shielding theory here, and only spend some time with ferromagnetic shielding. For simple shield geometries there are useful formulae which are simplified approximations to more elaborate formulae, some of which are shown in figure 1. More information on the spherical formulae can be obtained from details papers, found by working backward from references listed in a shielding paper [1]. The value of 0.7 for cubes has been determined by me from both theoretical arguments and experimental measurements [1]. One must be careful how these simplified formulae are used, and it is easy to be trapped into overdesigning a large shield. These formulae were derived assuming closed, continuous shells, that is, no holes, breaks, gaps, etc. Understandably, one would guess that if a shield were designed on the basis of, say, the spherical formula, then it must be a continuous, good sphere if the formula is to hold true. However, this is usually not the case; the spherical shell can have breaks and holes and the formula would still hold true. One way to understand this is as follows : Consider a single spherical shell with, say, $\mu=30,000, t=.0015 \mathrm{~m}$ and $d=2 \mathrm{~m}$, yielding $S=20$. Now let there be a circular hole in the shell of, say, $10 \mathrm{~cm}$ diameter. The leakage field at the sphere center due to this relatively small hole will certainly be far less than .05 of the outside field. One may guess that 10 such holes, regularly spaced, would still produce a negligible leakage at the center; of course, the leakage only 15 or $20 \mathrm{~cm}$ from a hole will be quite large, but at the center the small value of $S=20$ allows considerable leakage before the effectiveness of the shield has dropped significantly, say down to $S=15$. My experience with the Illinois room [1] showed that many short permalloy joints could be opened without significant reduction in $S$. With small $S$-values per layer, I would say that many hole-type openings can be tolerated, providing the openings do not blend to form a "long" continuous break.

In these formulae, $\mu$ can be increased by about a factor of 3 by shaking. Shaking is the process, known for many years, by which a separately applied alternating magnetic field in the shielding material keeps the domains in continuous motion and decreases their "friction". At Illinois we learned how to apply $60 \mathrm{~Hz}$ shaking to large-volume shields [2]. It is simple to use, and with this process a multi-layer shield can be turned on-and-off.

In figure 2, we apply the ferromagnetic shielding to the particuler case a two-layer cubical room. This

\section{A TYPIGAL TWO-LAYER GUBIGAL ROOM}

$$
\begin{array}{ll}
\begin{array}{l}
\mu=30,000 \text { (Hipernom, for example) } \\
t=.15 \mathrm{~cm}
\end{array} & d_{\mathrm{av}}=3 \mathrm{~m} \\
d_{0}-d_{\mathrm{i}}=.4 \mathrm{~m} & \frac{.7 \mu t}{d} \approx 10 \\
1-\frac{d_{\mathrm{i}}^{3}}{d_{0}^{3}} \approx .4 &
\end{array}
$$

With shaking both layers, $\mu \approx 70,000$, and $S \approx 200$.

FIG. 2. - Application of formulae from figure 1 to the case of the usual type of shielded room. 
is a typical shielded room, in the sense that there are perhaps 10 such rooms in the U.S. Without shaking, $S \approx 40$, a disappointingly low number for an expensive structure. With only moderate shaking of both layers $S$ can easily be raised to $\approx 200$. Generally, $S \approx 40$ was the state of the art when I designed the Illinois room in 1965. The Illinois room is shown in figure 3. Figure 4 shows the measured shielding factor

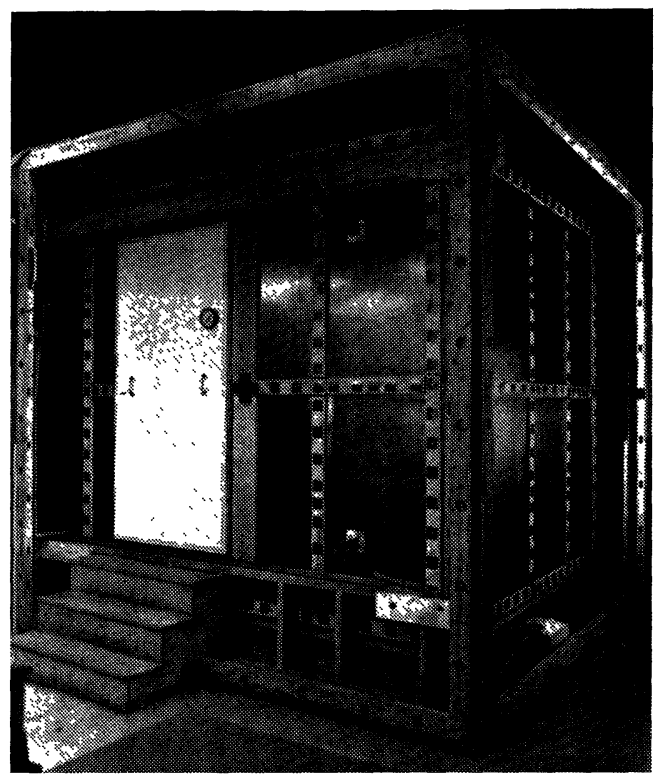

FIG. 3. - Photograph of the Illinois shielded room. The shaking coils, which thread through the shielding layers, are not seen here. The cubical wooden frame contains coils used in an active, negative-feedback system and in experiments of bucking the earth's field. There are three shielding layers : the outer two are of $.15 \mathrm{~cm}$ high $-\mu$ sheets, and the inner layer of $.5 \mathrm{~cm}$ aluminum.

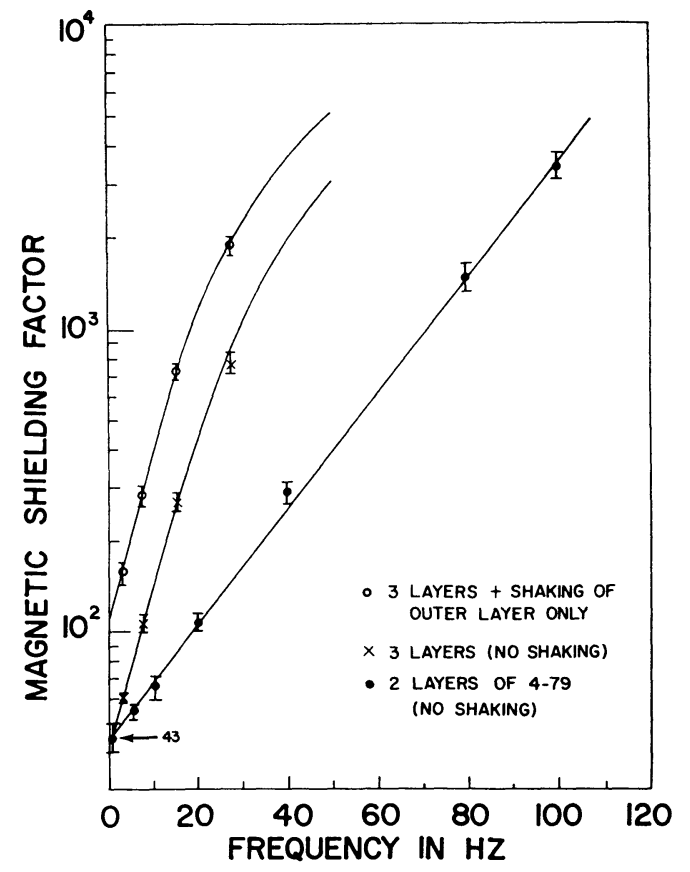

FIG. 4. - Measured performance of the Illinois room, showing shielding factor $S$ as a function of frequency. The external magnetic field at the lower frequencies was produced by a rotating magnet about $16 \mathrm{~m}$ from the room, and at the higher frequencies by a remote dipole coil fed by a power amplifier.
$S$ as a function of frequency. The increase of shielding factor with frequency is due to eddy-current shielding, mostly from the aluminum. The extra $S$ due to a one-dimensional active negative-feedback system is not included here; it increased $S$ by about a factor of 5 in the E.-W. direction, for remote disturbances. Other detailed studies of the Illinois room, beyond the $S$ measurements, are too lengthy to report here. The only other three-layer room known to me was built at the same time by Professor Norman Ramsay of Harvard; shaking and negative feedback were not used.

The factors which determine the lowest attainable fields in shields such as the Illinois room can be inferred from detector studies in that room. For my general purposes (biocurrent measurements), I used detectors with high sensitivities made possible by the existence of the low-frequency parametric amplifier. A typical detector consisted of a compact coil of, say, half a million turns of thin copper wire, enclosed in an electrostatic shield, and feeding the low noise Texas Instruments RA3A parametric amplifier. The lower sensitivity limit of these detectors was set by the white Johnson noise of the coil. Since RA3A was followed by an integrator to yield $B$ vs. $t$ instead of $\mathrm{d} B / \mathrm{d} t$ vs. $t$, the white noise appeared as $1 / f$ noise, as shown in figure 5. During the accumulation of that data the

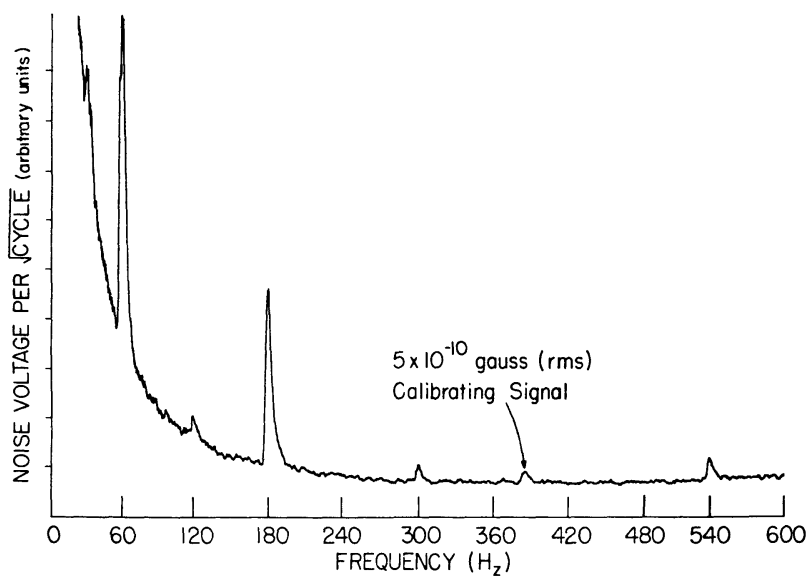

FIG. 5. - Integrated output of a coil detector in the Illinois room. $60 \mathrm{~Hz}$ and odd harmonics are due to residual field in the room from high background external to the room. The calibrating signal was produced by a dipole coil in the room. The limiting noise is seen to be $1 / f$ up to about $300 \mathrm{~Hz}$; at higher frequencies the input capacity of the amplifier complicates the spectrum. The resonant frequency is about $1500 \mathrm{~Hz}$. The $1 / f$ spectrum of the correct amplitude shows there was no noise contribution from the inner room walls.

background external to the room was all shielded out except for $60 \mathrm{~Hz}$ and its odd harmonics; this was accomplished by orienting the detector axis in the E.-W. direction, which had both the smallest external background and the active shielding system. The integrated detector output signal could then only be due to noise signals from the room walls and the detector input noise. The detector noise seen in figure 5 , at least above $10 \mathrm{~Hz}$, has the correct shape and amplitude for Johnson coil noise; it can be concluded that there is no significant contribution from the room walls and one can therefore set an upper limit to that form of noise. Since, if one wished, one 
can always increase the amount of shielding in building such rooms to drop the external background to any small value, it follows that the lower noise limit is set by noise generated from the inner walls. There are at least three mechanisms for noise production from the inner walls. The first may be called mechanical movement noise and is due to both mechanical, seismic vibration of parts of the inner magnetic wall and movements due to thermal expansions and contractions. All parts of the inner wall usually have a dc magnetic moment induced from the outside dc field against which they are shielding; any part of the inner wall which vibrates or moves with respect to a fixed point at the room center will, therefore, produce a changing magnetic field at that point. The second mechanism is Johnson noise; around closed conducting loops of the inner layer the Johnson voltage noise will produce a noise current which in turn will produce a magnetic noise at the room center. The third mechanism is thermal ferromagnetic noise; one guesses that thermally-induced rotations of domains would exist within the inner ferromagnetic wall, and these rotations would produce changing fields at the room center. I will not here present numbers and detailed arguments concerning these three mechanisms for noise production, but I will say that evidence from data such as figure 5 combined with engineering arguments leads one to believe that such noise can be kept below $1 \times 10^{-8}$ gauss (rms, including dc) at the center of a room especially designed and built to minimize this noise. That is, one can aim for this number as a reasonable and attainable limit of performance of large-volume conventional shields.

The Illinois room was not such a "limiting" room; not only was the mechanical movement noise very large, but the relatively low shielding factors allowed bothersome fields to penetrate from the external vertical and N.-S. directions. At MIT we decided to build a "limiting" room, and this room is now under construction.

III. The Shielded Room at MIT. - In consultation with the U.S. Office of Naval Research, we decided to aim for a room-size shield with the background
$|B| \lesssim 1 \times 10^{-8}$ gauss (rms, including dc) at the room center. The first technical determination we needed to make was the value of $S . \quad S$ was determined by first measuring the magnetic noise, shown in figure 6 , at a favorable location at the Francis Bitter National Magnet Laboratory. The ac rms noise during an
11:30 p.m

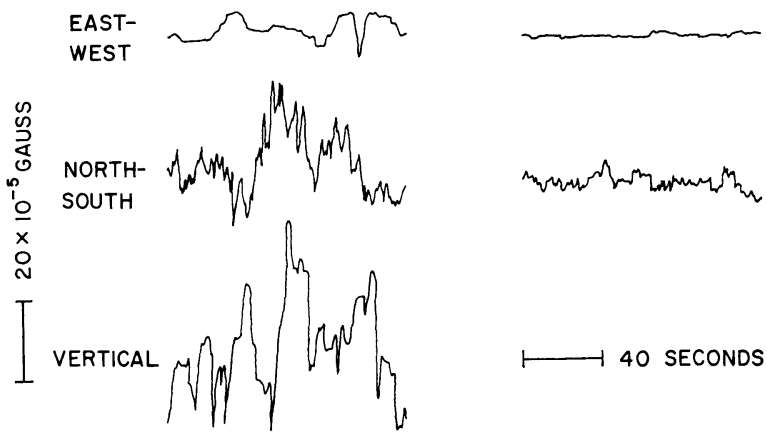

FIG. 6. - Magnetic ac noise at the Francis Bitter National Magnet Laboratory at night when all the highfield magnets are off. The noise drops after 1:00 a.m. because the electric trains stop running at that hour. Vertical noise at 1:30 a.m. is not included here.

average evening, from such measurements, was pessimistically assumed to be $15 \times 10^{-5}$ gauss, yielding a necessary $S=15,000$. Figure 7 shows what we felt was a reasonable and conservative division of about 15,000 among the three shielding methods.

How could we attain the raw ferromagnetic $S=400$ at a reasonable cost? Extending the Illinois-type cube to four layers might produce $S=400$, but at high cost and unappealing design. A better choise is a shape closer to a sphere. A cube is, after all, a bad geometry for a shield compared to a spherical shell. The corners reach out and bring in extra flux, and some of this extra flux leaks into the room, which is one way of understanding the drop from 1.3 to 0.7 in figure 1 . We liked the shape of the rhombicuboctahedron, shown in figure 11, which is a sort of geodesic sphere and looks octagonal when viewed from some

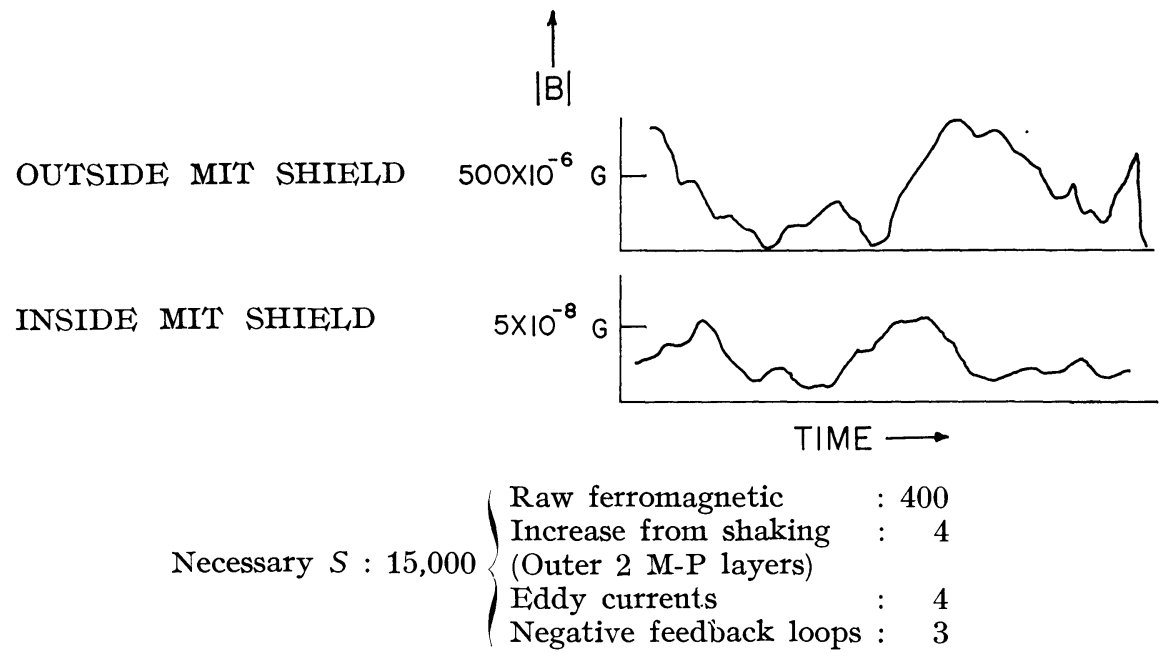

FIG. 7. - The upper curve was taken from data such as in figure 6 ; the lower curve shows our aim of $\sum_{1} 1 \times 10^{-8}$ gauss (rms, including dc). The right-hand numbers are a conservative estimate (too high) of what we need, averaged at about $10 \mathrm{~Hz}$. 


$\begin{array}{lccc} & \text { Cube } & \begin{array}{c}\text { Octagonal } \\ \text { strugture }\end{array} & \begin{array}{c}\text { Sphere } \\ S \text { of one layer }\end{array} \\ \text { Area of one layer } & \frac{.7 \mu t}{d} & \frac{1.1 \mu t}{d} & \frac{1.3 \mu t}{d} \\ \text { Area } / S \text { of one layer } & 6 d^{2} & 3.7 d^{2} & \pi d^{2} \\ \text { Relative cost } / S \text { of three layers } & 8.6 \frac{d^{3}}{\mu t} & 3.4 \frac{d^{3}}{\mu t} & 2.4 \frac{d^{3}}{\mu t} \\ \text { Relative cost } /(S \times \text { volume }) \text { of three layers } & 17.7 & 2.8 & 1.4 \\ \end{array}$

FIG. 8. - Comparison of a cube, rhombicuboctahedron and sphere. $d$ is the diameter of the sphere, outer face-toface spacing of the octagonal shape and length of a cubical side. The relative cost is taken to be proportional to the area of magnetic sheets. The octagonal structure is seen to be four times more efficient than a cube, for three layers, and with the same inner volume.

special directions. The economic advantage of this shape compared with a cube is shown in figure 8 . The dimensions we chose are shown in figure 9 , and figure 10 shows the thicknesses and materials of the

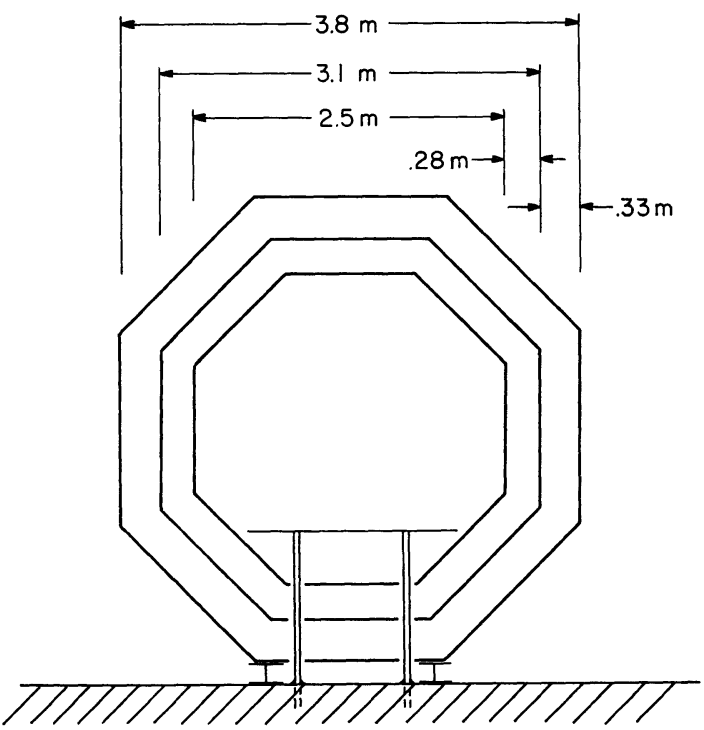

FIG. 9. - Dimensions of the three high- $\mu$ layers of the MIT shielded room. The floor suspension is mechanically isolated from the shielding; this is a necessary feature of some of the planned experiments in the room.

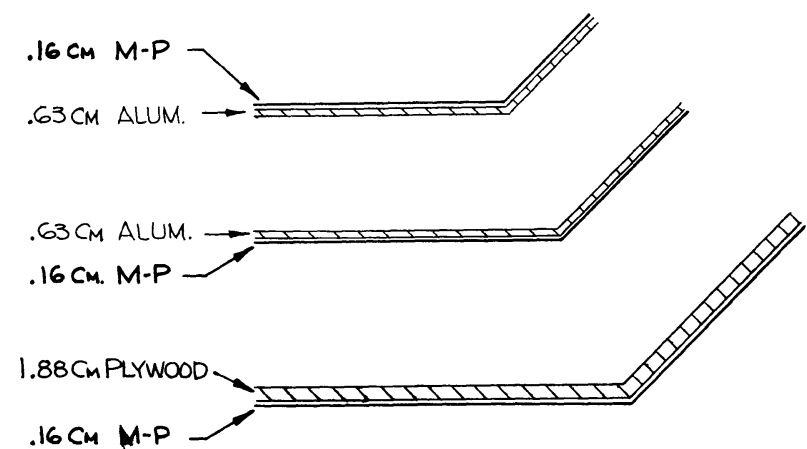

FIG. 10. - Thickness and materials of the walls of the MIT shielded room. The two layers of aluminum act as a rigid mechanical framework and as eddycurrent shields as well as mounting for moly-permalloy.

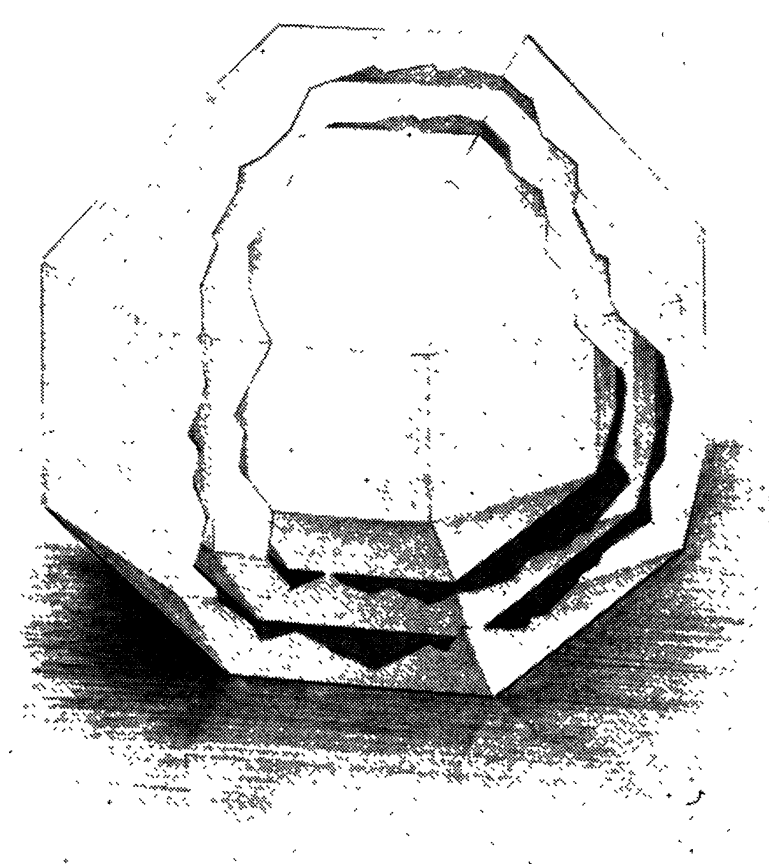

FIG. 11. - Cutaway drawing of the MIT shielded room showing the three layers of magnetic sheets. The rhombicuboctahedron shape has 18 identical squares and 8 identical triangles. Doors and other details are not shown here.

various layers. The inner two layers of high- $\mu$ sheets, including Hipernom and moly-permalloy are screwed onto aluminum shells. Aluminum was structurally chosen not only for mechanical rigidity and eddycurrent shielding, but also to cope with the problem of the variation of the remnant dc field with shield temperature, found to be a severe problem with a plywood backing for the moly-permalloy. We believe that the plywood troubles do not arise from the thermal coefficient of expansion of wood, but from the variation of dimensions with moisture content which apparently is a sensitive function of temperature.

Most of the construction of the shielded room is being funded by the U.S. Office of Naval Research and the Damon Runyon Memorial Fund for Cancer 
Research. The room will be a national facility, available to government, universities, and industry. It will be initially used for magnetometer testing, testing for nonmagnetic materials, and measurements of ion currents in the human brain and heart. Other uses will undoubtedly appear. We invite members of this conference to contact us when needs arise for a shielded facility of this type.

\section{REFERENCES}

[1] Cohen (D.), A Shielded Facility for Low-Level Magnetic Measurements, J. Appl. Phys., 1967, 38, 1295.
[2] CoHEN (D.), Enhancement of Ferromagnetic Shielding against Low-Frequency Magnetic Fields, Appl. Phys. Letters, 1967, 10, 67. 